\title{
Development of High-precision Micro CNC Machine with Three-dimensional

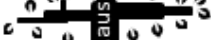 要 auSMT: Measurement System
}

\section{Chih-Liang Chu*, Tzu-Yao Tai, Yun-Hui Liu, Chin-Tu Lu, Chen-Hsin Chuang and Hong-Wei Liao}

Department of Mechanical Engineering, Southern Taiwan University, Tainan, Taiwan

(Received 12 January 2012; Accepted 13 February 2012; Published on line 1 June 2012)

*Corresponding author: cliang@mail.stut.edu.tw

DOI: 10.5875 /ausmt.v2i2.138

\begin{abstract}
This study aims at developing a machine center consisting of high-speed micro-milling machine, micro-EDM and coordinate measuring machine. The machine center uses a commercially available PC-Based CNC controller and micro-EDM power supply. The structure design is based on an open L-shaped granite base, where a Z-axis platform is mounted on the top of an L-type base, while $X$ and $Y$-axis platforms are assembled by stacking. Additionally, a fuel tank, WEDG winding mechanism and a work piece holder were fixed to the X-axis work platform. Three-axis positioning stages use servomotors to drive lead screws for motion control. Equipped with a commercially available PC-Based CNC controller, any processing path and precision motion control can be achieved. In addition, the Z-axis platform includes a commercially available rapid adapter for the rapid assembly of C-axis rotation, high-speed micro-milling spindle and three-dimensional measuring probe. This means that the machine can quickly switch between micro-EDM, high-speed micro-milling and three-dimensional measurement. The machine center successfully produced micro probes with a front-end sphere with a diameter of less than $100 \mu \mathrm{m}$. Combined with a self-developed trigger circuit, it also completed a three-dimensional touch trigger probe. The measurement software was developed with Borland $\mathrm{C}++$ Builder. Integrating the three-dimensional touch trigger probe with the three-axis linear scale, the three-dimensional coordinates of the measured values were calculated and processed. It has been successfully applied to the measurement of point, line, circle and angle.
\end{abstract}

Keywords: micro EDM; high-speed milling; micro 3D CMM; WEDG; touch-trigger probe

\section{Introduction}

As technology advances and people seek products offering lighter weight and convenience, the main development of products such as flat-panel displays, flexible electronics, biochips, micro-gear, and micro-sensors is trending toward miniaturization. Currently, the main micro-fabrication technology includes four processing methods: (1) lithography technique process, where the light source can be an X-ray, electron beam, or UV light; (2) excimer laser processing; (3) micro-machining; (4) silicon micro-machining process.
According to the existing literature on Electrical Discharge Machining (EDM), when creating micro probes, the micro-EDM process has many advantages. It not only doesn't need additional mold design, but also creates finished products with anti-wear and high accuracy. In addition, micro-EDM can be utilized to process a wide variety of products including ink jet printer heads [1], micro-nozzles for atomizing film production [2], micro-vias [3], miniaturized biomedical products such as micro-delivery devices and micro-fluidic mixers [4], micro-biochips [5], and micro-pumps [6]. Therefore, in order to complete the processing of micro-components, Chen [7] developed a multi-task small computer numerical control (CNC) machine. The machine has the 
Chih-Liang Chu was born in Taiwan, on February 20, 1968. He received the Ph.D. degree in mechanical engineering from the National Taiwan University, Taiwan in 2002 with a work design and fabrication of a Nano Coordinate Measurement Machine. He joined Industrial Technology Research Institute, Opto-Electronics \& Systems Laboratories, Taiwan in 1996, where he worked in the Data Storage Technology Department, which was involved in the R\&D on advanced computer peripheral devices, such as DVD optical pickup, data storage, and printer. He is now with Southern Taiwan University, Tainan, Taiwan, working as a professor \& chairman in Department of Mechanical Engineering. His current research interests are in the fine actuation mechanism and precision machine design, optical measurement probe development and active vibration control technology etc.

Professor Tzu-Yao Tai joined the faculty of Southern Taiwan University, Department of Mechanical Engineering in 2004. His research work on material science and manufacturing process has made him an expert in the areas of precision machine development. He has published more than 10 refereed papers and has some cooperation with industry. Currently he is the director of precision machine research and development center at Southern Taiwan University. His objectives, now and for the future, is to promote a deeper understanding between mechanical properties of materials and manufacturing processes, and to enhance the development of precision machine in Taiwan.

Yun-Hui Liu received his Ph.D. in the field of acoustics from Nation Taiwan University, in 1997, and his research work was the adaptively active control on the acoustic field in a circular duct. He joined the faculty of the Southern Taiwan University (STUT) after working in industry for several years, and he is now an Associate Professor in the Department of Mechanical Engineering. His research areas of interest include active noise and vibration control, monitoring and diagnostics of mechanical equipments, vibration isolation technologies, and mechatronics. From 1998 to 2001, he was a researcher in Vibration and Acoustics Laboratory at Center for Measurement Standards, Industrial Technology Research Institute (ITRI), before joining STUT in 2001. His research work in ITRI mainly covers the establishment of calibration and measurement capabilities in the fields of Acoustics, Ultrasound, and Vibration.

Chin-Tu Lu received the B.S. and M.S. degrees in power mechanical engineering from the National Tsing Hua University, Hsinchu, Taiwan, and the Ph.D. degree in mechanical engineering from the University of Texas at Austin in 1993. From 1986 to 1988 he served as a Second Lieutenant Instructor at the Chinese Naval Marine Engineering School, Kaohsiung, Taiwan. Currently he is an Associate Professor of Department of Mechanical Engineering and Institute of Mechatronics at Southern Taiwan University, Tainan, Taiwan. His teaching and research interests involve computer-aided design and engineering, finite element analysis, structural analyses of machinery, contact mechanics, tribology, electrical contacts, and electromechanics.

Cheng-Hsin Chuang received his B.S. degree and Ph.D. degree from the National Cheng Kung University (NCKU) in 1995 and 2002, respectively, both in Civil Engineering. He then held the Postdoctoral research scholarship with the Center for Micro/Nano Science and Technology at NCKU, where he held the lead position in the core facilities for MEMS fabrication and Nanotechnology. In 2004, he joined the Micro Systems Technology Center at Industrial Technology Research Institute (ITRI), where he conducted the development of MEMS microphone and SAW-based biosensor. In 2005, he was recruited by the Department of Mechanical Engineering at Southern Taiwan University as an Assistant Professor. Currently, he is an Associate Professor and the Director of Micro and Nano Sensing Technology Lab (MANST Lab) and Roll-to-Roll Imprinting Center for Flexible Optoelectronic Devices (RicFod). His research interests focus on flexible tactile sensors, Roll-to-Roll imprinting technology, and DEP chips for single-cell-based and nanoparticles-based biosensors. He has published over 100 papers in different international journals and conferences and owned 10 patents in biosensor and tactile sensor. Dr. Chuang won two Special Awards of HIWIN Thesis Award in 2007 and 2008 as well as two best conference paper awards of $3^{\text {rd }}$ IEEE NEMS in 2008 and Taiwan automation conference in 2010. His two patents won Gold Medal Award and Silver Medal Award of Taipei International Invention Show \& Technomart Invention Contest in 2010 and 2011, respectively.

Hong-Wei Liao received Master's. degree from Department of Mechanical Engineering at Southern Taiwan University in 2008. Currently, he is a doctoral student for Department of Mechanical Engineering at Southern Taiwan University. functions of micro-milling, electrochemical discharge compound micro-processing, current fluid polishing and electrode inspection. It can be used for the fabrication of micro-molds, biochips, and micro-channels with high aspect ratio structure. At present, most foreign commercial micro-machines are single-function and expensive. The multi-function machines will be even more expensive and lacking in technical precision. Taiwan mainly relies on imported expensive machines, indicating that as yet there are no equipment vendors to invest in the multi-micro machines. Therefore, this study will develop a machine center consisting of high-speed micro-milling machine, micro-EDM and micro-coordinate measuring machine. Through its micro-EDM and high-speed micro-milling, various optical structure patterns will be produced on a roller surface to solve the discontinuous issue of the roller mold. With a three-dimensional measuring system for online real-time measurements, it can achieve effective mass production of optical-grade structure roller type molds.

\section{Operational Principles}

\section{Machine structure design}

The machine structure in this study is divided into four parts: the base, Z-axis cantilever, adapter and the fuel tank, as schematized in Figure 1 . The overall size is $660 \times 840 \times 770 \mathrm{~mm}^{3}$. The basic structure of the machine is composed of a base and a Z-axis inverted L-shaped cantilever. Both are made of granite. X- and Y-axis platforms are designed and assembled as a stacking platform. The adapter used is EROWA's manual quick adapter. The fuel tank is designed to be approximately $600 \times 370 \mathrm{~mm}$. In addition, the WEDG line rail supply mechanism is fixed to the $\mathrm{X}$-axis work platform. The take-up system is hung on the left side of the fuel tank as shown in Figure 2 . This design can save a lot of space and help reduce the volume of the machine.

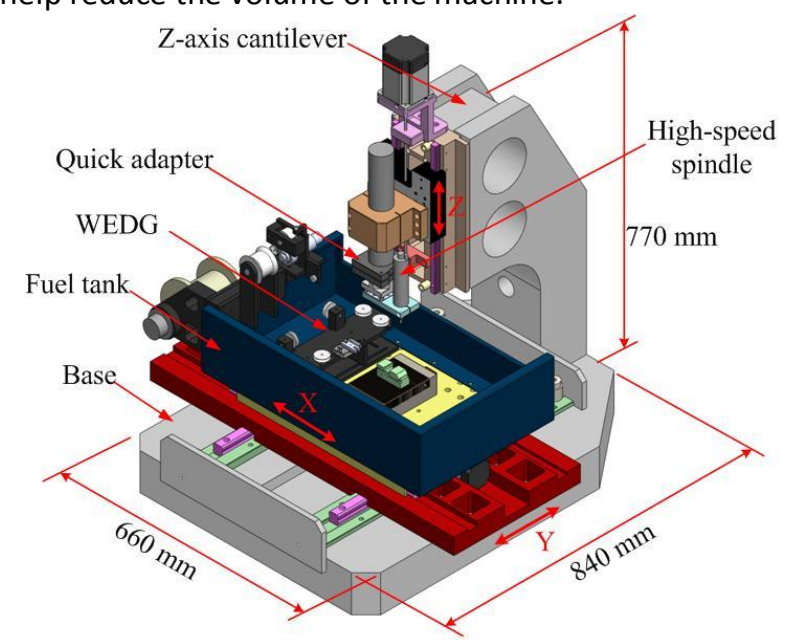

Figure 1. Schematic of the overall structure. 


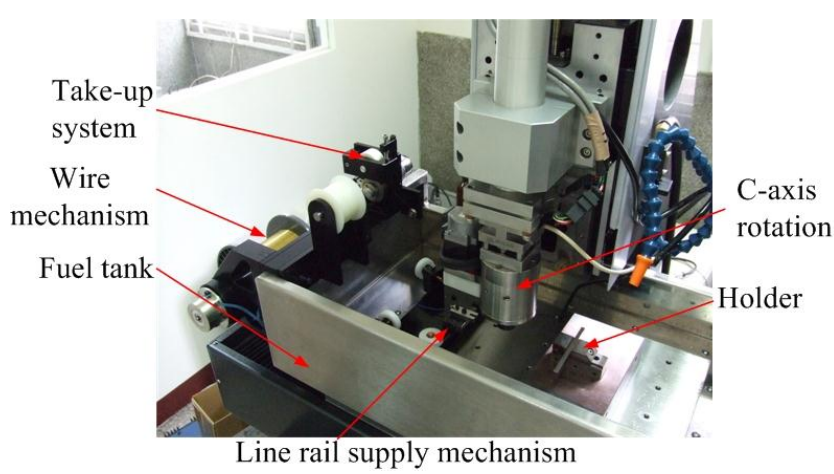

Figure 2. Photograph of WEDG line rail supply system

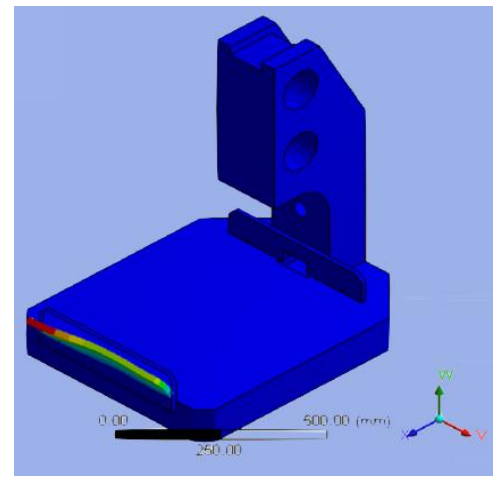

Figure 3. First mode.

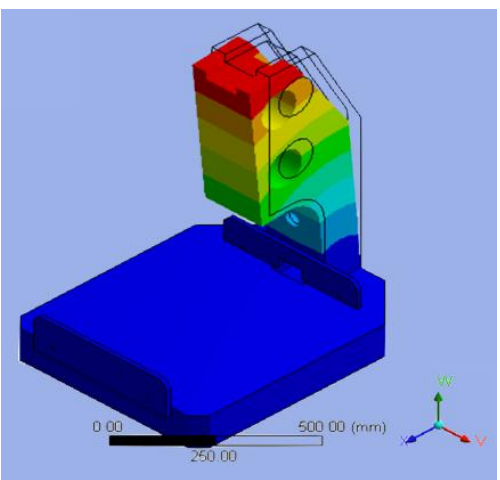

Figure 4. Eighth mode.

Table 1. Natural frequencies.

\begin{tabular}{|l|l|}
\hline & Frequency \\
\hline Mode 1 & $82.96 \mathrm{~Hz}$ \\
\hline Mode 2 & $147.23 \mathrm{~Hz}$ \\
\hline Mode 3 & $396.17 \mathrm{~Hz}$ \\
\hline Mode 4 & $605.39 \mathrm{~Hz}$ \\
\hline Mode 5 & $814.55 \mathrm{~Hz}$ \\
\hline Mode 6 & $1060.5 \mathrm{~Hz}$ \\
\hline Mode 7 & $1166.8 \mathrm{~Hz}$ \\
\hline Mode 8 & $1383.1 \mathrm{~Hz}$ \\
\hline
\end{tabular}

ANSYS finite element software is used for analysis in this study. To reduce processing and measurement errors and structural damage due to vibration interference, it must be designed to avoid the occurrence of resonance as shown in Figures 3 and 4. In this study, the $\mathrm{C}$-axis rotation of the electrical discharge machine was about $4000 \mathrm{rpm}$ for processing, and the high-speed spindle reached a maximum speed up to $80,000 \mathrm{rpm}$. The corresponding frequencies were $66.67 \mathrm{~Hz}$ and 1333 $\mathrm{Hz}$, respectively. Natural frequencies of the basic structure simulated by ANSYS modal analysis are listed in Table 1. According to the first eight frequencies, it will be able to select the working frequency range of a motor for the machine.

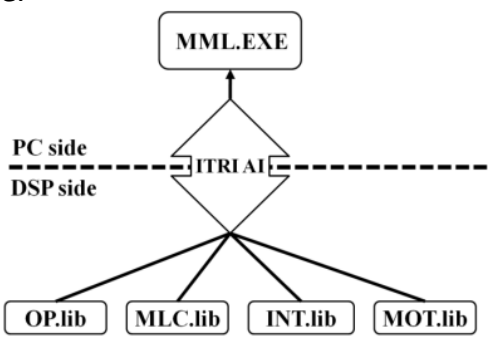

Figure 5. Schematic of PC-based CNC control system software.

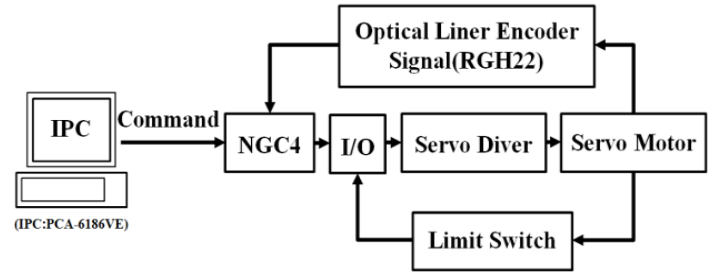

Figure 6. Schematic of single-axis control.

\section{Three-axis positioning platform with CNC controller}

This study adopts a PC-Based CNC Controller, developed by the Industrial Technology Research Institute. The DSP side of the controller consists of four modules, including the operation module, mechanical logic control module, interpreting module and movement module. The functions of the four modules are integrated into a running program. Through the user interface module of the PC side, PC-based CNC control system software will be integrated, as shown in Figure 5. Figure 6 shows a schematic of single-axis control. Industrial PCs set the given displacement command through the NGC-axis card to drive the servo motor driver and then platform displacement. Optical linear scale for position measurement and feedback is installed on the other side of the platform. Through the NGC-axis card, the AB-Phase signal generated by the linear scale is used for error calculation, and ultimately for the closed-loop control to achieve accurate positioning. Regarding the hardware used, the CNC control box is from Lien Sheng Mechanical \& Electrical Co., Ltd. It contains the power supply of a micro-electrical discharge machine and PC-Based CNC Controller. Figure 7(a) is the schematic diagram for the EDM control system, and Figure 7(b) shows the PC-Based CNC control box. 


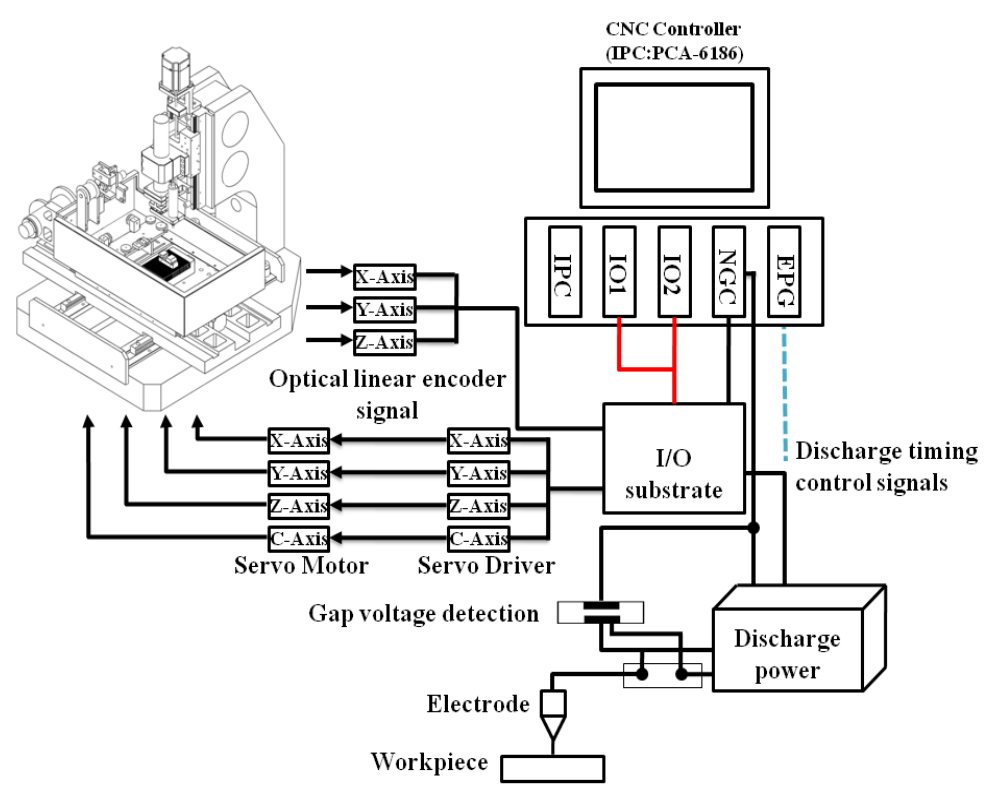

(a)

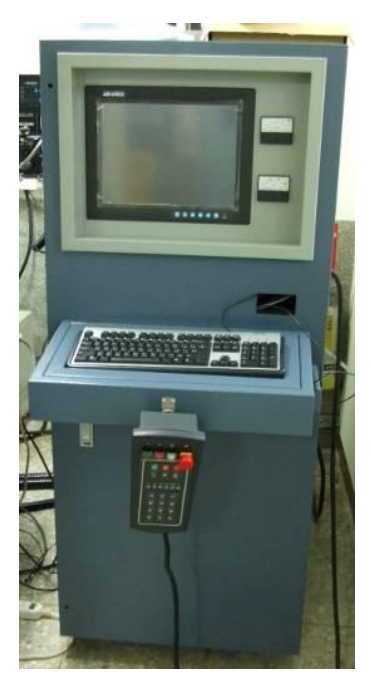

(b)

Figure 7. (a) Schematic of EDM control system; (b) Photograph of PC-Based CNC control box.

\section{Micro EDM Equipment}

The EDM power supply in this study is accompanied by a WEDG mechanism. As shown in Figure 8 , it is mainly divided into a line supply mechanism, a line guide mechanism, a pulling motor mechanism, a line closing mechanism, and a C-axis rotation, which is singled out in Figure 9. The rotation accuracy and positioning accuracy of the $\mathrm{C}$-axis rotation is $1 \mu \mathrm{m}$, driven by a servomotor. The motor can rotate $360^{\circ}$ for positioning and angle split. In processing, the probe is clamped onto the C-axis for rotation, while the line guide mechanism transfers a wire electrode for electrical discharge machining. The U-shaped slot has fixed wire electrodes to minimize vibrations and to facilitate the improvement of processing accuracy. Figure 10 shows the schematic for the EDM. In our study, a micro-probe with a front-end ball having a diameter less than $100 \mu \mathrm{m}$ was successfully produced, as shown in Figure 11 . The roundness is up to $3 \mu \mathrm{m}$.

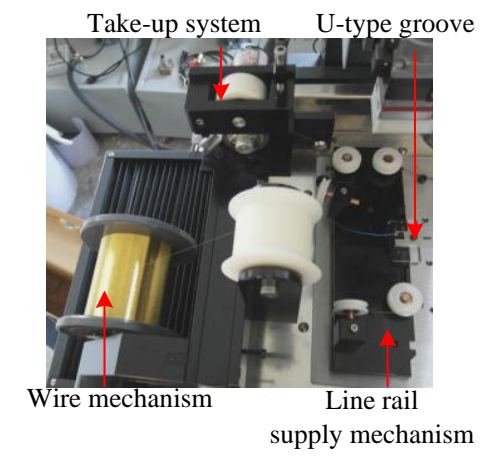

Figure 8. Photograph of WEDG mechanism.

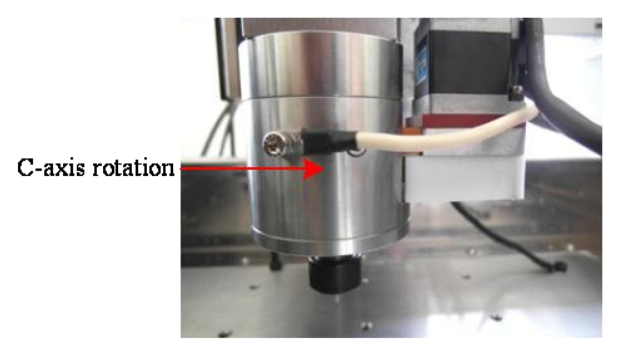

Figure 9. Photograph of C-axis rotation.

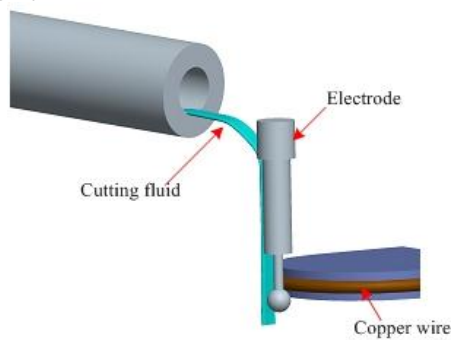

Figure 10. Schematic of wire electrical discharge grinding (WEDG).

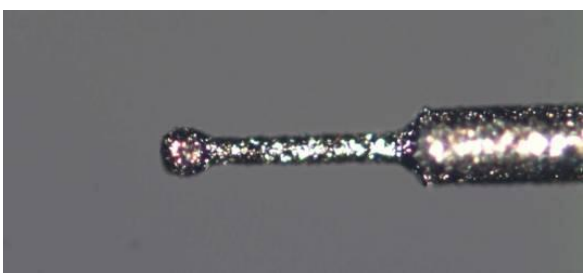

Figure 11. Photograph of a microprobe with ball diameter less than 100 $\mu \mathrm{m}$.

In addition, we successfully designed a discharge circuit using a transistor to control the capacitors. The control loop circuit is used to detect the capacitor's voltage and spacing, and then decides whether to activate the transistor and the discharge process. Figures 12 and 13 show the discharge circuit and the control circuit. 


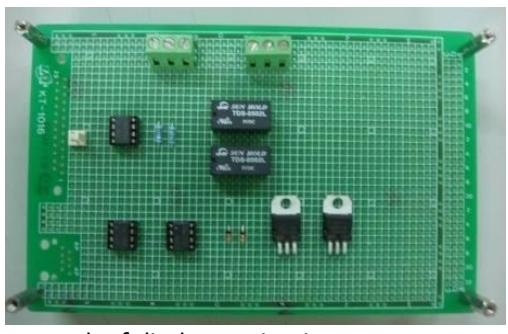

Figure 12. Photograph of discharge circuit.

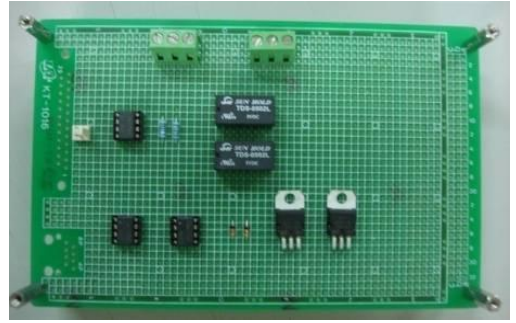

Figure 13. Photograph of control circuit.

\section{High-speed micro-milling equipment}

The high-speed spindle is pneumatic and has a maximum speed of $80,000 \mathrm{rpm}$. It can be used for EDM with a WEDG mechanism and for high speed drilling. A quick adapter is used for the rapid functional exchange between the $\mathrm{C}$-axis rotation and three-dimensional measurement probe. A photograph of the high-speed spindle is shown in Figure 14.

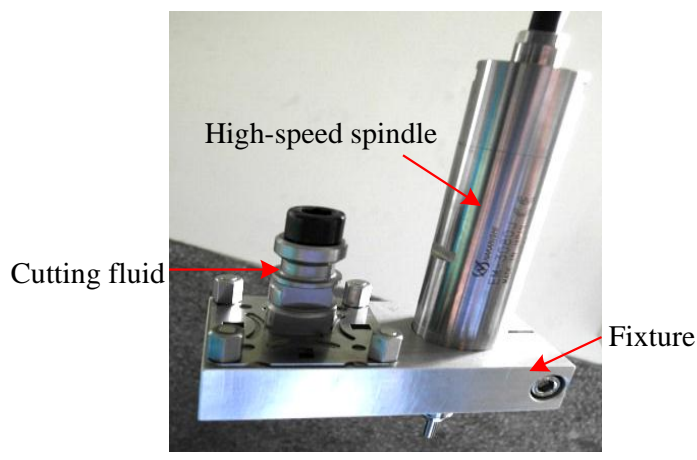

Figure 14. Photograph of high-speed spindle.

\section{Three-dimensional measurement system}

This system also contains a probe trigger circuit to trigger the measurement. The design takes advantage of low energy (low voltage, low current) and conductive characteristics of metals. Essentially, the circuit removes the capacitor in the discharge circuit, while keeping the transistors always on. When the probe contacts the work piece, the resistor in a parallel circuit is conducted and the resistor's voltage is detected as a trigger basis. Figure 15 shows the circuit diagram and the change of the trigger signal.
The micro probe, with a front sphere of diameter less than $100 \mu \mathrm{m}$, was produced by micro-EDM. The probe is clamped in a small three-jaw chuck as shown in Figure 16.

Measurement software used was developed by Borland $\mathrm{C}++$ Builder. Integrated with three-dimensional touch trigger probe and three-axis linear scales, the trigger probe measures and calculates the values of the three-dimensional coordinates. Three-dimensional measurement software was applied to take the measurements of point, line, circle, and angle as shown in Figure 17.

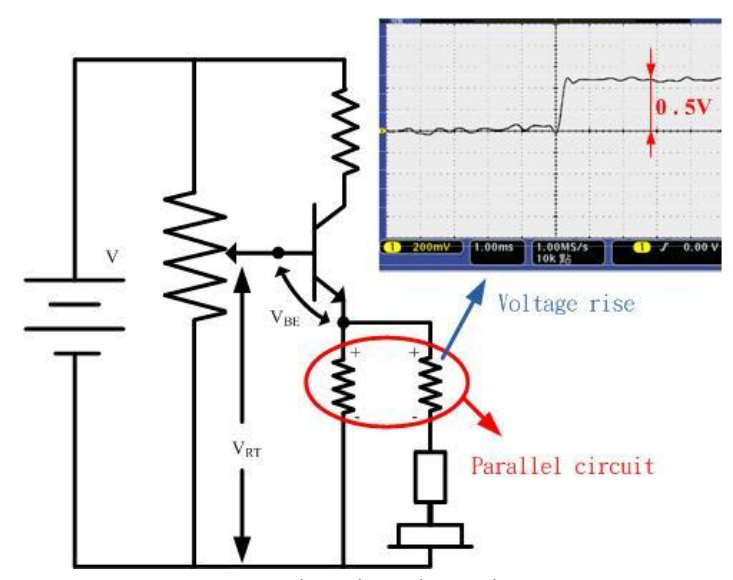

Figure 15. Circuit is on when the voltage changes.
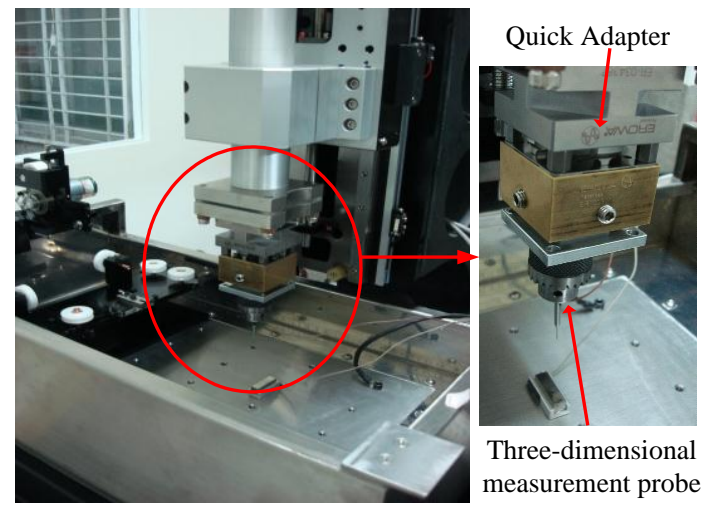

Figure 16. Photograph of three-dimensional measurement probe.

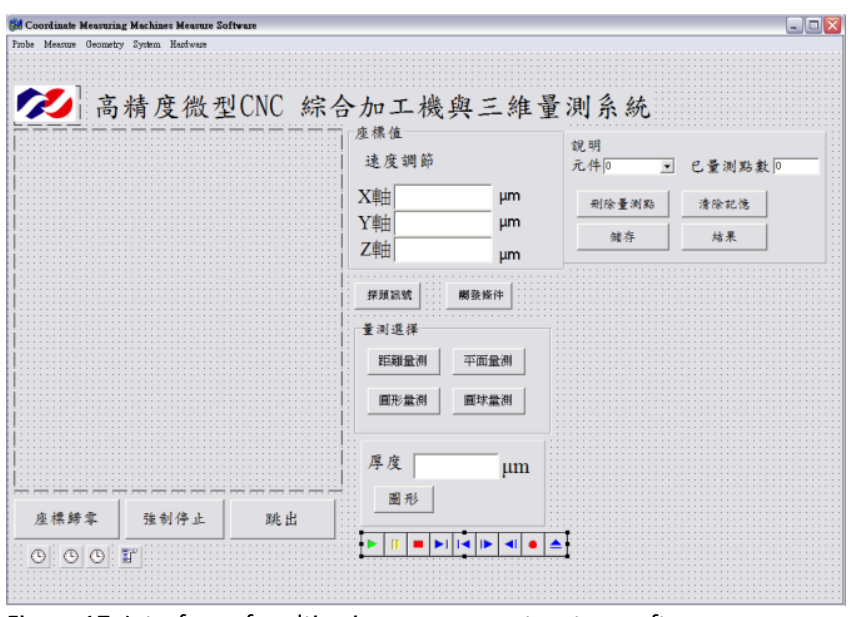

Figure 17. Interface of multi-axis measurement system software. 


\section{System Integration and Measurement Results}

\section{Width measurement for gauge block}

The integration of hardware was installed in the CNC machine center (as shown in Figure 18) for the actual measurement. Gauge blocks of $9 \mathrm{~mm}$ in width were used for measurement. The measurement method is shown in Figure 19, and the measurement results are listed in Table 2. The measurements have a maximum value of about $9.0117 \mathrm{~mm}$, and a minimum value of about $9.0099 \mathrm{~mm}$, with a standard deviation of $0.56 \mu \mathrm{m}$.

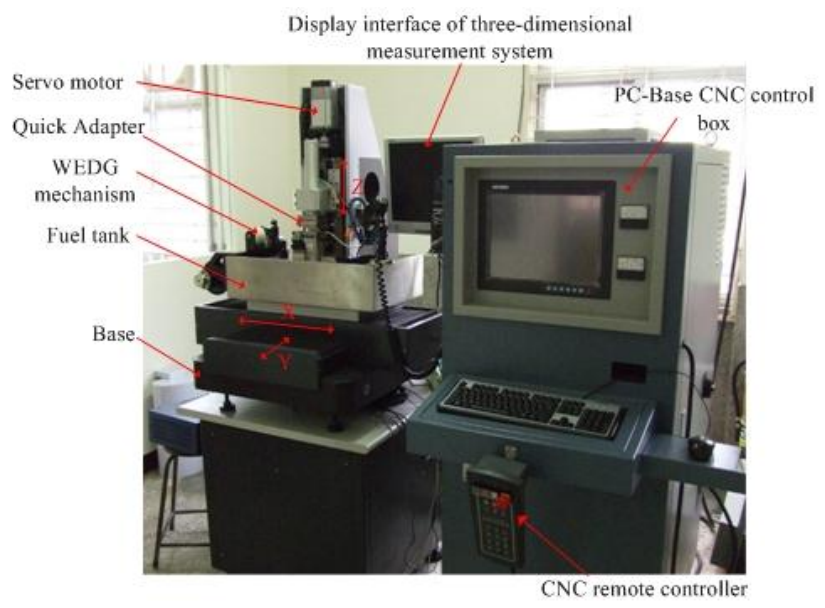

Figure 18. Photograph of the high-precision CNC machine.

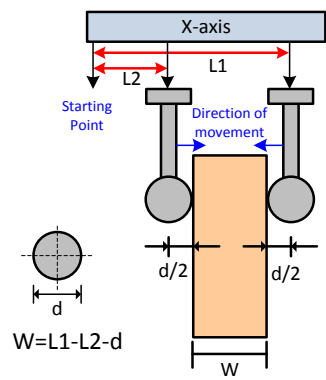

Figure 19. Schematic of the width measurement.

Table 2. Results of width measurement.

\begin{tabular}{|l|l|l|l|l|}
\hline $\begin{array}{l}\text { Meas. } \\
\text { No. }\end{array}$ & $\mathrm{L} 1(\mathrm{~mm})$ & $\mathrm{L} 2(\mathrm{~mm})$ & $\mathrm{D}(\mathrm{mm})$ & $\mathrm{w}(\mathrm{mm})$ \\
\hline 1. & 74.0461 & 64.9362 & 0.1 & 9.0099 \\
\hline 2 & 74.0485 & 64.9377 & 0.1 & 9.0108 \\
\hline 3 & 74.0564 & 64.9448 & 0.1 & 9.0116 \\
\hline 4 & 74.0516 & 64.9401 & 0.1 & 9.0115 \\
\hline 5 & 74.0602 & 64.9485 & 0.1 & 9.0117 \\
\hline 6 & 74.0232 & 64.9118 & 0.1 & 9.0114 \\
\hline 7 & 74.0242 & 64.9133 & 0.1 & 9.0109 \\
\hline 8 & 74.0186 & 64.9082 & 0.1 & 9.0104 \\
\hline 9 & 74.0013 & 64.8905 & 0.1 & 9.0108 \\
\hline Average & 74.0367 & 64.9257 & 0.1 & 9.0110 \\
\hline
\end{tabular}

\begin{tabular}{|l|l|l|l|}
\hline Step & $\begin{array}{l}\text { Average of nine } \\
\text { measurements } \\
(\mathrm{mm})\end{array}$ & $\begin{array}{l}\text { Standard } \\
\text { Deviation } \\
(\mu \mathrm{m})\end{array}$ & $\begin{array}{l}\text { Precision } \\
(\mu \mathrm{m})\end{array}$ \\
\hline $0 \rightarrow 1$ & 1.0006 & 1.25 & 0.556 \\
\hline $1 \rightarrow 2$ & 1.0006 & 3.36 & 0.588 \\
\hline $2 \rightarrow 3$ & 1.0007 & 2.89 & 0.700 \\
\hline average & 1.00063 & 2.50 & 0.6147 \\
\hline
\end{tabular}

\section{Conclusion}

This study has successfully developed a CNC machine center consisting of a high-speed micro-milling machine, a micro-EDM, and a micro-coordinate measuring machine. A commercially available adapter is used to quickly switch the functions of micro-EDM, high-speed micro-milling and three-dimensional measurements while online. This machine has successfully processed micro-probes with a sphere diameter less than $100 \mu \mathrm{m}$. With the self-developed trigger circuit, a three-dimensional measurement system was completed. This study has demonstrated how to combine traditional and non-traditional machining and micro-measurements in the same machine, which can complete a variety of processing with high accuracy. 


\section{Acknowledgement}

The authors are grateful to the National Science Council (NSC), Taiwan, Republic of China, for the financial support under the Contract NSC 99-2632-E-218-001-MY3.

\section{References}

[1] K. H. Choi, A. Khan, K. Rahman, Y. H. Doh, D. S. Kim, and K. R. Kwan, "Effects of nozzles array configuration on cross-talk in multi-nozzle electrohydrodynamic inkjet printing head," Journal of Electrostatics, vol. 69, no. 4, pp. 380-387, 2011. doi: 10.1016/i.elstat.2011.04.017

[2] K. P. Rajurkar, G. Levy, A. Malshe, M. M. Sundaram, J. McGeough, X. Hu, R. Resnick, and A. DeSilva, "Micro and nano machining by electro-physical and chemical processes," CIRP Annals - Manufacturing Technology, vol. 55, no. 2, pp. 643-666, 2006. doi: 10.1016/j.cirp.2006.10.002

[3] S. T. Chen, Z. H. Jiang, Y. Y. Wu, and H. Y. Yang, "Development of a grinding-drilling technique for holing optical grade glass," International Journal of Machine Tools and Manufacture, vol. 51, no. 2, pp. 95-103, 2011. doi: 10.1016/j.ijmachtools.2010.12.001
[4] Y. Liu, X. W. Shi, E. Kim, L. M. Robinson, C. K. Nye, R. Ghodssi, G. W. Rubloff, W. E. Bentley, and G. F. Payne, "Chitosan to electroaddress biological components in lab-on-a-chip devices," Carbohydrate Polymers, vol. 84, no. 2, pp. 704-708, 2011.

doi: $10.1016 /$ j.carbpol.2010.03.038

[5] S. Julich, M. Riedel, M. Kielpinski, M. Urban, R. Kretschmer, S. Wagner, W. Fritzsche, T. Henkel, R. Möller, and S. Werres, "Development of a lab-on-a-chip device for diagnosis of plant pathogens," Biosensors and Bioelectronics, vol. 26, no. 10, pp. 4070-4075, 2011. doi: $10.1016 /$ i.bios.2011.03.035

[6] Z. R. Xu, C. G. Yang, C. H. Liu, Z. Zhou, J. Fang, and J. H. Wang, "An osmotic micro-pump integrated on a microfluidic chip for perfusion cell culture," Talanta, vol. 80, no. 3, pp. 1088-1093, 2010. doi: 10.1016/j.talanta.2009.08.031

[7] S. T. Chen, "Development of a low-cost composite film technique for functional micro-tools," Thin Solid Films, vol. 519, no. 15, pp. 4742-4748, 2011. doi: 10.1016/j.tsf.2011.01.027 